\title{
SURGERY OF MITRAL INCOMPETENCE
}

\author{
C. N. Barnard, M.D., Ph.D. \\ Cardiothoracic Surgeon, Senior Lecturer, Department of Surgery. \\ V. Schrire, M.B., Ph.D.(Cape Town), M.R.C.P., F.R.C.P.E. \\ Cardiologist, Senior Lecturer, Department of Medicine, Groote Schuur Hospital, and \\ University of Cape Town
}

Mitral valve disease has for many years been accepted as the commonest sequel of rheumatism, both clinically and pathologically. The development of stenosis has never been in question. Such has not been the case, however, with incompetence, though as long ago as 1849 Hope first drew attention to this condition. The existence of mitral incompetence as an entity or even as an important component of the disease was soon challenged and early in this century, largely through the teachings of Graham Steell (1906), Sir James McKenzie (1916), Cabot (1926) and Sir Thomas Lewis (1933), the diagnosis of mitral incompetence fell into disrepute. With the development of cardiac surgery, however, mitral incompetence has once more come into its own.

Three major hæmodynamic disturbances of the mitral valve have now been recognized. Pure mitral stenosis is the commonest and most readily recognized clinically and pathologically (Wood, 1954). The valve leaflets are fused at the commissures and though the chordæ and papillary muscles are diseased the valve mechanism is usually not grossly abnormal. The condition is generally amenable to closed-heart surgery with some form of mechanical dilator. Pure mitral incompetence is the least common and is not difficult to diagnose. Deficiency of valve leaflet tissue, dilatation of the annulus or a combination of both is generally present, but the valve mechanism remains relatively normal so that repair under cardiac by-pass is generally possible. The combination of stenosis and incompetence is frequently encountered but varying amounts of each component produce a spectrum of hæmodynamic conditions. On the one hand dominant stenosis with minimal incompetence lends itself to closed-heart surgery, whereas dominant in-

From the Departments of Surgery and Medicine, University of Cape Town and Groote Schuur Hospital and Cardiac Clinic, Council for Scientific and Industrial Research Cardiopulmonary Group, Groote Schuur Hospital. competence with trivial stenosis is amenable open-heart surgery. Where both severe stenosis and severe incompetence are present the valvie structures are generally grossly disorganized and anything short of complete valve replacement probably ineffective. Pre-operative assessment of the exact hæmodynamic situation may be exo tremely difficult even with the help of cardiac catheterization and angiocardiography.

Though by far the commonest, rheumatism not the only cause of organic mitral incompetene Bacterial endocarditis, usually subacute, frequentlo complicates mild rheumatic mitral valve dise accentuating valve scarring and destruction, $\subseteq$ 黑 valves may be affected de novo. Surgicalyproduced mitral incompetence is not rare and occasionally the resulting incompetence is so severe that the patient is worse off after valvotom than before. Lastly, congenital mitral incompe tence, with or without other heart defects, may be encountered, the most common example being that associated with the cleft mitral valves of endocardial cushion defects (partial common atrio ventricular canal). Mitral incompetence due to fibroelastosis or endomyocardial fibrosis is beyon the scope of this discussion.

In this paper we wish to record the clinica recognition, surgical approach and preliminary operative results in rheumatic mitral incompes tence, surgically-induced mitral incompetence्छ and congenital mitral incompetence.

\section{Rheumatic Mitral Incompetence}

Our patients represent a group of highty selected cases from a large clinic draining an arẹa where rheumatic heart disease is common (Schrir? 1958) and where 330 closed-mitral valvotomies have been performed, 125 during the two years under review. Eleven patients were chosen $f$ open-heart surgery. Selection was based on the clinical assessment of pure incompetence in ten (confirmed in every case) and dominant re-stenosis with slight incompetence in one. No patient was 


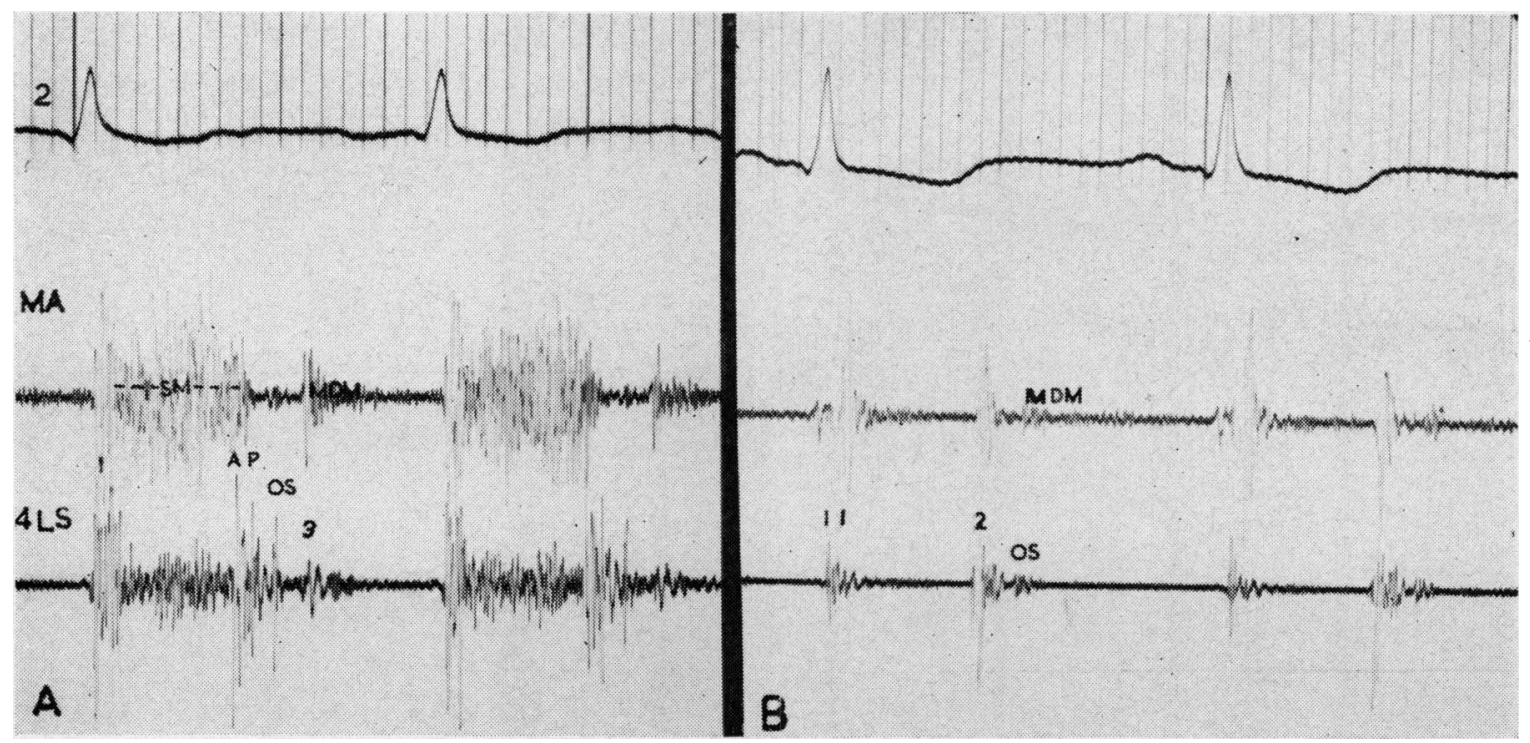

Fig. I.-Pre- and post-operative phonocardiograms in a patient with severe mitral incompetence. Atrial fibrillation is present prior to, and sinus rhythm after surgery. At the mitral area (MA) prior to surgery (A) there is a pansystolic murmur, a soft opening snap (OS), a loud third sound (3) and a short mid-diastolic murmur. The systolic murmur continues beyond the aortic component of the second sound, which is obscured at the mitral area but shown at a synchronously recorded tracing, taken at the fourth left intercostal space (4LS). Splitting of the second sound is normal. After surgery (B) the systolic murmur has practically disappeared; the opening snap is soft; the third sound has disappeared and a short mid-diastolic murmur remains.

advised surgery in whom the lesion was thought to be mixed stenosis and incompetence with grossly disorganized valves. In every case disability was increasing progressively despite full and active medical therapy (Grade 3 or 4 ), and several patients were in the late stages of heart failure.

\section{Clinical Features of Pure Mitral Incompetence}

Females outnumbered males by 6 to $I$, and the age ranged from 17 to 44 with the majority between 20 and 30 years. A history of at least one attack of rheumatic fever, often several, was present in all but one patient. Subacute bacterial endocarditis occurred in three patients, one of whom had several attacks. Symptoms due to pulmonary congestion were present in every patient, all but two having paroxysmal cardiac dyspnœa. Angina pectoris was present in two patients and systemic embolism in one. Although palpitation was not a major complaint, patients were always aware of the hyperdynamic overactive left ventricle. The first observation made in the post-operative period was the disappearance of the pounding in the chest.

Atrial fibrillation was present in every patient, tricuspid incompetence, jugular venous distension and hepatomegaly in half. The pulse was usually normal in most patients, though on occasion a slight collapsing element was noted. Hypertension was absent.

Palpation was of the greatest value. In every patient considerable left ventricular enlargement was present with an overfilled hyperdynamic thrust in the fifth or sixth intercostal space usually beyond the anterior axillary line. A systolic thrill was often present. Rocking movement of the chest suggested an aneurysm of the left atrium in three patients. Right ventricular over-activity was absent in most subjects.

Auscultation revealed a loud (Grade 3 to 4 of six grades) pan-systolic murmur in every case, maximal at the apex radiating widely into the axilla and left base posteriorly and medially to the parasternal area. The murmur commenced with the first sound which was often drowned and continued through or beyond the aortic component of the second sound. A third sound was heard and recorded in every case, followed by a short, soft (Grade $I$ to 2 of four grades) middiastolic murmur. An opening snap was heard in two and recorded in four subjects (Fig. I) and did not correlate strictly with the mobility of the anterior mitral cusp nor with operability (Nixon, Wooler and Radigan, 1960).

Trivial aortic incompetence was present in one subject clinically and in three at surgery. In one, 


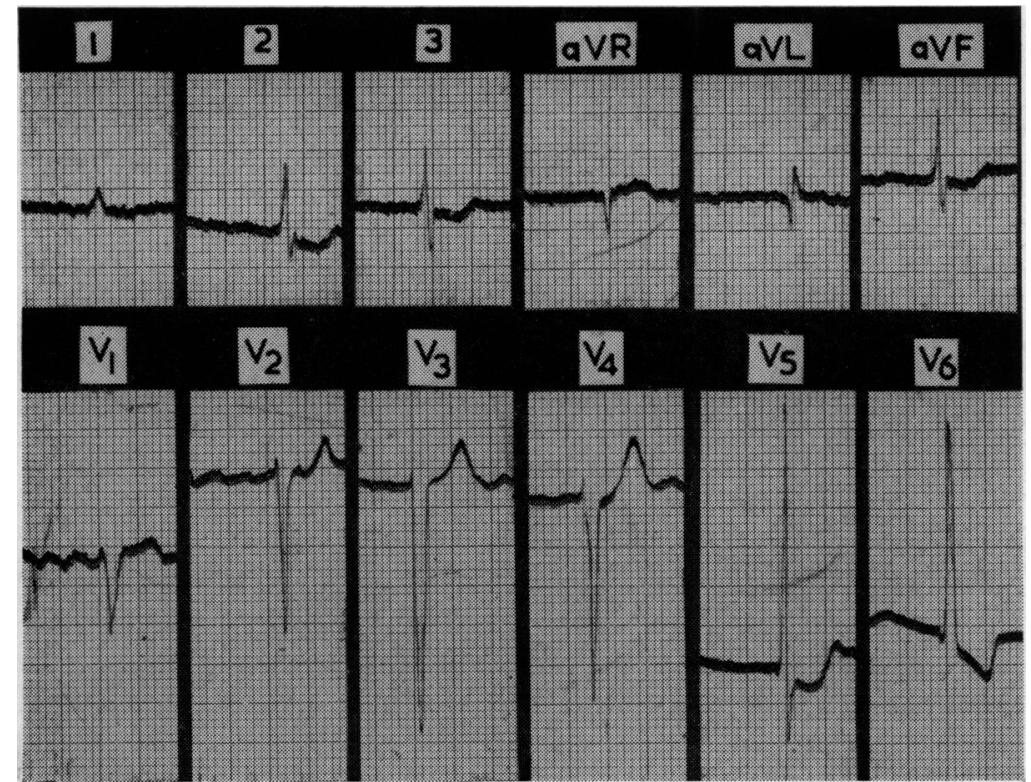

FIG. 2.-Electrocardiogram in mitrô incompetence showing atrial fibrillation and digitalis effect on severe left ventricuf hypertrophy.

moderate aortic incompetence was present, and in one there was aortic stenosis and incompetence with a gradient of $50 \mathrm{~mm}$. across the aortic valve. Significant tricuspid incompetence was present in two patients though transient tricuspid murmurs occurred more often.

The electrocardiogram confirmed the presence of atrial fibrillation in every patient and in only one was this the sole abnormality. One patient had complete right bundle branch block and the remainder showed digitalis effect on left ventricular hypertrophy (Fig. 2). The presence of left ventricular overload excludes any significant mitral stenosis in the absence of other causes of enlargement such as aortic incompetence. Tracings taken during sinus rhythm showed left atrial hypertrophy.

Radiologically gross or aneurysmal enlargement of the left atrium was found eight times (Fig. 3). Such a finding strongly suggests dominant mitral incompetence though we have encountered giant left atrial enlargement at necropsy in the presence of pure tight stenosis. Left ventricular enlargement was present in all patients, indicating severe mitral incompetence. Valve calcification was not seen.

\section{Mixed Stenosis and Incompetence}

Though only one patient with this combination was submitted to surgery in this series, the physical signs are well known. Pure mitral stenosis is associated with an apex beat in the normal site, tapping in quality with a diastolic or pre-systolic thrill, a lift over the outflow tract of the right ventricle and a palpable pulmonary second sound. The characteristic auscultato findings are loud first sound, second sound fof lowed by opening snap, diastolic and pre-sys lic murmurs producing an unforgettable caderce. Systolic murmurs are generally absent unless have radiated from the tricuspid or aortic valveg. In pure mitral incompetence, on the other hane, the apex is displaced outwards, left ventricular type, thrusting hyperdynamic in quality, ass ciated with systolic thrill, little lift over the right ventricle and an impalpable pulmonary secone sound. The characteristic auscultatory finding are a pan-systolic murmur, starting with the fir sound which is not accentuated, continuing through to the second sound, and a third sounge followed by diastolic murmur which is short and soft. Occasionally an opening snap is also heard.

When both stenosis and incompetence age present the signs consist of a combination of the two. The apex is usually left-ventricular with a diastolic thrill and there is a lift over the right ventricle. There is a pan-systolic murmur assiciated with a third heart sound and loud mif diastolic murmur. The greater the stenosis the more the signs resemble pure mitral stenosis, añ vice versa.

The electrocardiogram usually shows left atrif hypertrophy when sinus rhythm is presen. There may be no evidence of ventricular hypeq trophy, right or left ventricular hypertroph Radiological examination is usually not of great help in determining the nature of the dominafl valve lesion. 

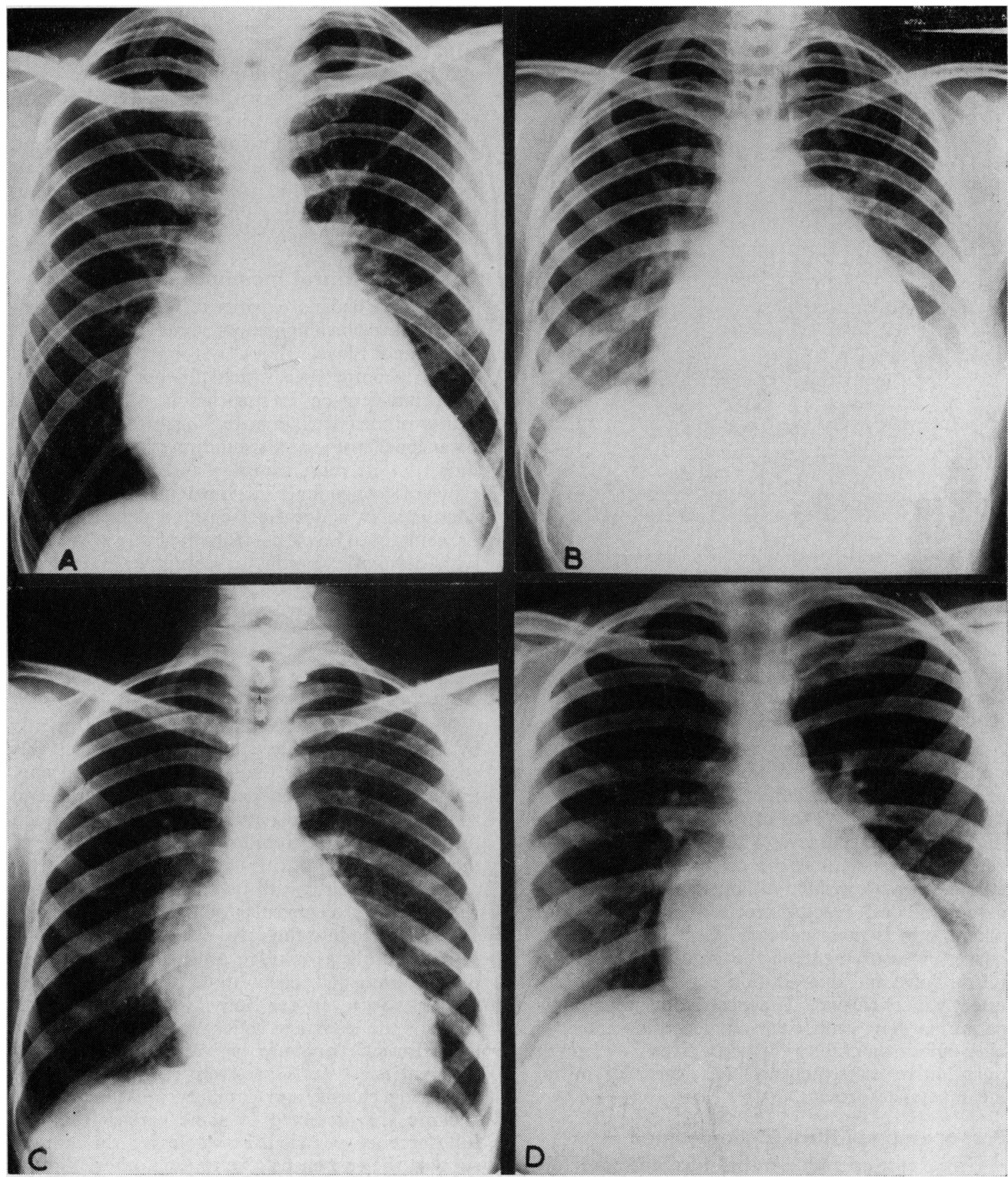

Fig. 3.-A-D X-rays from four patients with severe mitral incompetence showing moderate to gross cardiomegaly, marked left atrial and left ventricular enlargement. Hilar congestion of varying degree is also present. 


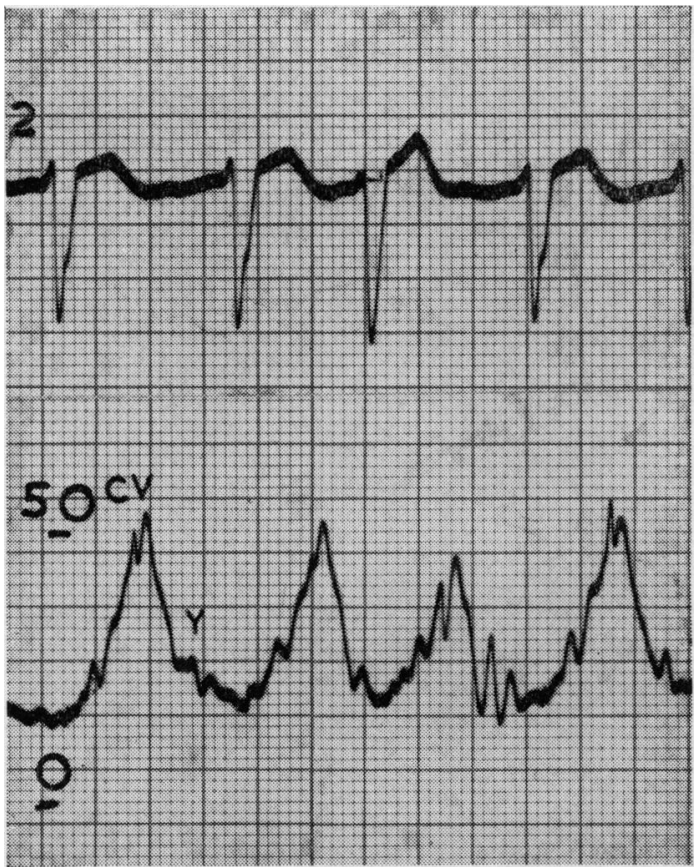

FIG. 4.-Pulmonary wedge tracing showing a raised pulmonary venous pressure with a $C V$ wave of $45 \mathrm{~mm}$. and a brisk $\mathrm{Y}$ descent characteristic of severe mitral incompetence. Atrial fibrillation is present.

\section{Cardiac Catheterization and Angiocardiography}

Special investigations were unnecessary and not performed in any of our subjects. In the majority of patients, pure or dominant stenosis, or pure or dominant incompetence can be recognized with a high degree of accuracy. When in doubt catheterization may sometimes be of help. Right heart studies (Fig. 4), with or without exercise, generally give equivocal results precisely in those cases where help is most needed. Left atrial pressure curves, measurement of the gradient across the mitral valve and dye dilution curves are also frequently inconclusive. The most promising investigation is left ventricular angiocardiography or cinèangiocardiography which gives a rough quantitative assessment of the degree of mitral incompetence present.

\section{Post-operative Mitral Incompetence}

Gross post-operative mitral incompetence following closed mitral valvotomy is fortunately rare. In our experience this has become commoner since the introduction of the mechanical dilator, particularly in cases with re-stenosis. Clinical recognition is easy. In the first place the surgeon is generally immediately aware of the fact that he has produced too much incompetence by teas $\overline{\text { - }}$ ing a cusp or opening a commissure too widely. Secondly, the post-operative course is storm, with the patient developing pulmonary congestion and heart failure and responding poorly to tre ment. Lastly, the signs of severe mitral incorr. petence with a left ventricular thrusting apex and a loud pan-systolic mitral are immediately evidere.

There were two patients with intractable heaft failure in this series, in one of whom incoro petence had developed following a second valva tomy for re-stenosis.

\section{Congenital Mitral Incompetence}

We have had no experience with isolated comgenital mitral incompetence (Starkey, 1959; Talnew, Stern and Sloan, 196r), but have encounter mitral incompetence which did not require sư ${ }^{2}$ gical interference in association with corrected transposition (Beck, Schrire, Vogelpoel, Nellen and Swanepoel, 196r) and secundum type atrial septal defect. The most common and most important type of congenital incompetence is that encountered in endocardial cushion defects, parti⿳⺈ or complete (Edwards, 1960). Sixteen patients with acyanotic, partial or complete endocandfal cushion defects have been submitted to surgerb. The clinical features of these conditions -aide described elsewhere (Sellors and Somergites 196r; Barnard and Schrire, 196r).

\section{Anatomy and Pathology}

Normal mitral valve closure is effected main by the freely mobile anteromedial leaflet; this cusp is much longer than the posterolateral on $\vec{\theta}$. Since its chordæ are only attached to the peripheral zone, a triangular area at the base, which is mu勇 thinner, is left free to billow towards the cavity of the left atrium during systole. The shortgr posterolateral cusp with its chordæ inserted moge widely on its ventricular surface moves only short distance into the valve orifice during systolo. It acts mainly as a ridge or shelf against which the anteromedial cusp abuts to effect closuse (Brock, 1952; van der Spuy, 1958). The movement of the leaflets is activated by the differen in hydrostatic pressure between the atrium arit the ventricle. It is passively restrained by the anchoring chordæ and papillary muscles. These anchors are protected to some extent from the full force of ventricular systole by the mutugh support the two cusps give to each other (Fig.

Although several different pathological lesions may result in incompetence of the mitral value, the essential cause is deficiency of leaflet tissue either absolute or relative, or a combination of both. An absolute deficiency of leaflet tissue ma्d 


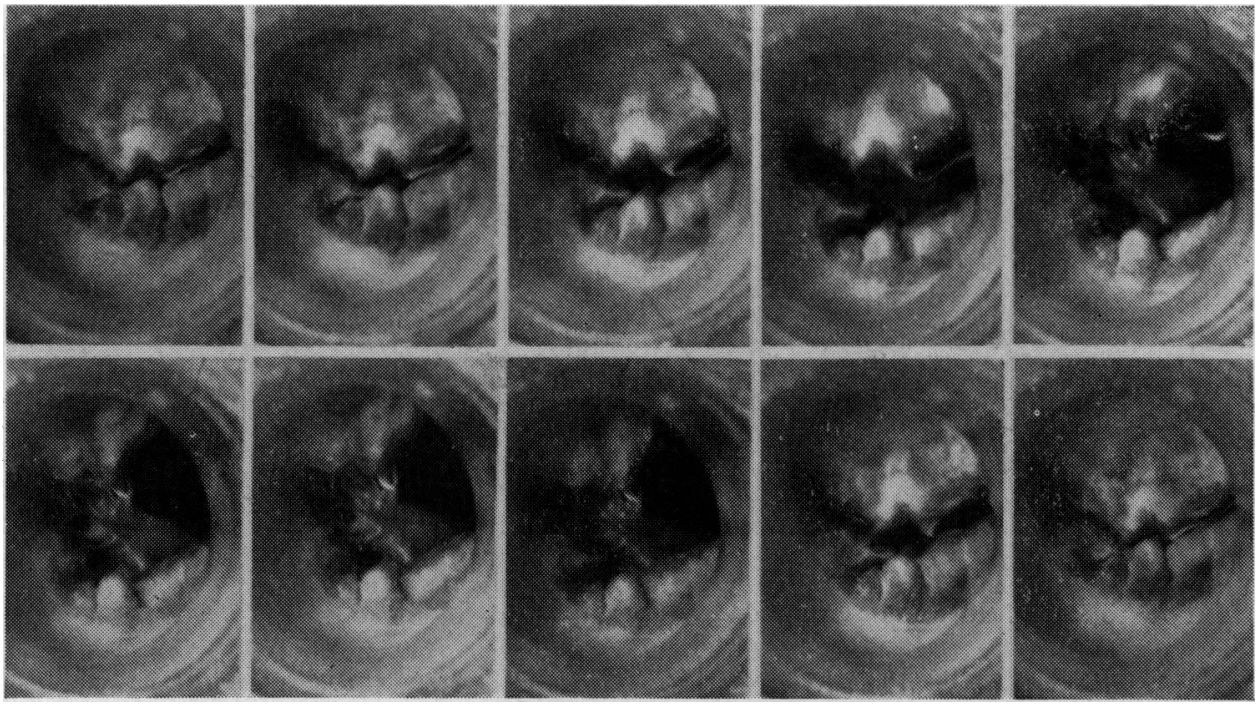

result from a cleft, perforation or tear of a cusp (Fig. 6), but more commonly from rheumatic scarring of the cusps. The posterolateral leaflet of the mitral valve is more susceptible to the ravages of the rheumatic process (Fig. 7). However, this may be more apparent than real because of the greater length of the anteromedial cusp. Thus the same degree of rheumatic involvement of both leaflets from their free margins to their bases will involve only one-third of the anteromedial leaflet while the posterolateral cusp will become almost completely rigid. In such a case, 


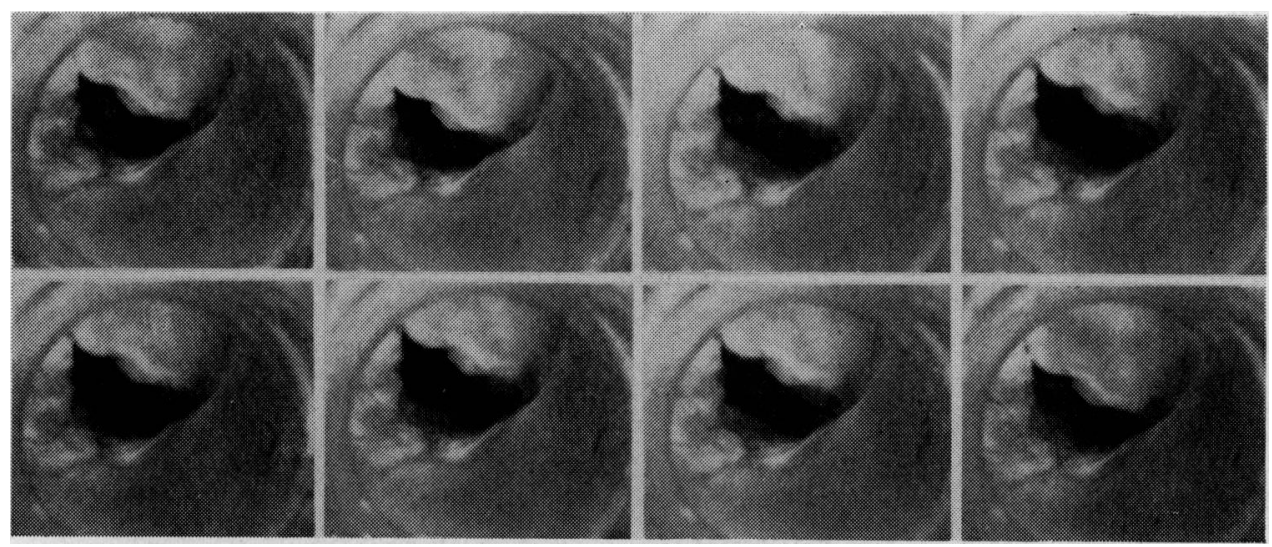

Fig. 7.- Cycle of incompetent mitral valve movement showing the extensive scarring of the posterolateral leaflet and the immobility of the anteromedial leaflet.

although the middle and basal thirds of the anteromedial leaflet remain thin and flexible, the shelf provided by the posterolateral leaflet is lost. With each systole the anteromedial leaflet overrides the posterolateral one and incompetence results.

Relative deficiency may be due to dilatation of the annulus. The two leaflets are thus moved farther apart and although there may be no actual loss of leaflet tissue, the distance the cusps have to move to meet is too great for the tissue available. Inflammatory changes in the junctional tissue causing thickening, shortening and fusion of the chordæ with limitation of cusp mobility will also result in relative deficiency of cusp tissue.

\section{Surgical Techniques}

In his approach to mitral incompetence, irrespective of the rtiological factor, the aim of the surgeon should be to restore any relative or absolute deficiency of leaflet tissue that may exist. This can usually be achieved by one or more of the following techniques:

A. Repair of cleft, hole or tear in mitral leaflets which may be present.

B. Mobilization of the anteromedial cusp.

C. Provision of a posterior shelf or support to the anteromedial cusp.

D. Insertion of a complete prosthesis.

\section{A. Repair of Cleft, Hole or Tear in Mitral} LEAFLETS

A hole or tear in one or other leaflet of the mitral valve resulting in an absolute deficiency of leaflet tissue can be repaired by direct suture or the use of a plastic patch. However, the correction of mitral regurgitation from a cleft anteromedial leaflet as found in endocardial cushion defects often needs more than the simple sutuore described by certain surgeons (Cooley, Kirklin and Harschbarger, 1957; Cooley, Latson and Keats, 1958; McGoon, DuShane and Kirklin, 1959; Barnard, Phillips, De Villiers, Casserley Hewitson, Van der Riet and McKenzie, I95\%. In most of these cases free mobility of the anteromedial leaflet is not present and before comolese competence can be restored mobilization ofot tre cusp is necessary (vide infra).

B. Mobilization of the ANTERomedial Cứp

As the anteromedial cusp is the "main flap' the closure of the mitral orifice during systole, free mobility of this leaflet is essential. The froe movement can be prevented by fusion of the commissures, rigidity of the leaflet or sub-valvu旬r fibrosis. Thus to give maximum mobility, the following avenues can be explored:

(i) Separation of fused commissures.

(ii) Removal of calcium from the leaflet.

(iii) Treatment of sub-valvular changes intê․ fering with cusp mobility.

\section{(i) Separation of Fused Commissures}

Although commissural separation either by blunt or by sharp dissection may increase the mobility of the anteromedial cusp, this manœu woe may increase regurgitation if performed when there is annular dilatation. In these circumstances the fusion of the two leaflets at their commissures prevents further annular dilatation and acts as an annuloplasty (vide infra). When this restraint ${ }^{\prime} s$ broken the two cusps move further away from each other, thus increasing the distance which the anteromedial leaflet has to extend to close the orifice. Commissurotomy is only of value when the annulus is normal in size or smaller then normal. 


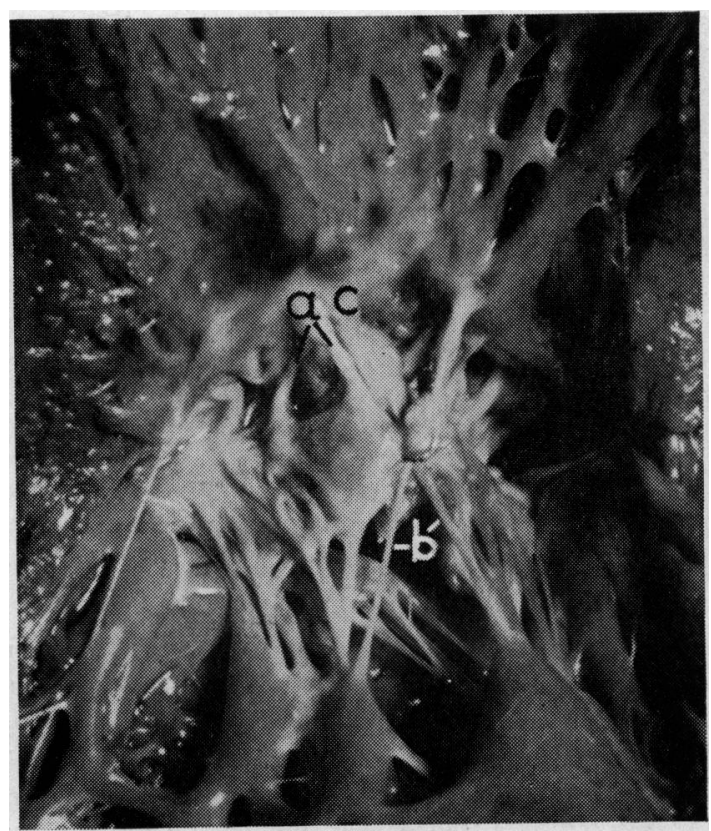

FIG. 8.-Congenital cleft mitral valve after closure by direct suture showing the abnormal restraints (a, $\mathrm{b}$ and c) preventing free mobility of the central trigone (from 'The Surgical Correction of Endocardial Cushion Defects'. C. N. Barnard and V. Schrire (196I): Surgery, 49, 4, 500-509. Published by C. V. Mosby Co., St. Louis).

\section{(ii) Removal of Calcium from the Anteromedial Leaflet}

Free mobility of the trigone of this leaflet may be prevented by plaques of calcium. Once these rigid areas are broken up by gentle crushing and the bits of calcium carefully removed, the leaflet will again swing freely like a sail with ventricular systole.

\section{(iii) Treatment of Sub-Valvular Changes Preventing Cusp Mobility}

As discussed in the section on the normal anatomy and function of the mitral valve, the chordx of the anteromedial leaflet are attached only to the periphery of the cusp allowing free mobility of the central trigone. In most cases of endocardial cushion defects, abnormal restraints of the cleft tie this portion of the valve down (Edwards, 1960; Barnard, 196r; Barnard and Schrire, 196I) (Fig. 8). These prevent free mobility of the trigone and therefore, even after careful suturing of the cleft, regurgitation will persist unless these restraints are divided and the cusp is mobilized.

In incompetence following rheumatic valvulitis, chordo-papillary fusion restricts the move- ment of the anteromedial leaflet. An attempt should be made to free the cusp by breaking down these adhesions. Direct finger-tip pressure may sometimes suffice but it may be necessary to separate the papillary muscles by sharp dissection. In some cases the shortened, retracted chordæ of the posterolateral leaflet can be divided, allowing more mobility of the chordæ of the anteromedial leaflet. This will not cause inversion of the posterolateral cusp during ventricular systole as severe fibrosis will have made this cusp a passive ridge.

C. Provision of a Posterolateral Shelf Which Will Effect Closure and Provide SUPPORT FOR THE ANTEROMEDIAL CUSP

The importance of the provision of a posterolateral shelf in the treatment of mitral insufficiency has been recognized by many workers. Substances such as pericardial tubes (Moore and Schumacker, 1953), vein grafts (Henderson and Law, 1953) and tendon grafts (Glover, Henderson, Martutti and Gregory, 1952) have been placed in the posterior commissure to provide such a shelf in the area where regurgitation is maximal. Ridged Ivalon sponge (DeWall, Warden, Lillehei and Varco, 1956; Glenn, Gentsch, Hume and Guilfoil, I956) a mobile Ivalon sponge sling (Johns and Blalock, 1954), and a baffle of lucite (Harken, Block, Ellis and Dexter, 1954) have been placed in the mitral orifice with the same object in mind. Approximation and elevation of the posterior aspect of the mitral valve will have the same effect, and this has been attempted using pericardial strips (Bailey and Bolton, 1956), vein slings (Sakakibara, 1955), and silk sutures (Kay and Cross, 1955; Nichols, 1957). The use of an artificial cusp in place of the posterolateral leaflet was suggested by Brock in 1952, and reported by Gott and others in 1957. All these procedures have the same common aim in that they attempt to provide a buttress against which the anteromedial cusp can meet and close during ventricular systole.

If incompetence persists after the surgeon has fully mobilized the anteromedial leaflet, it means that the anteromedial flap is still not capable of moving across the valve orifice to close against the posterolateral shelf. The leak can only be corrected or lessened now by providing such a shelf. Improvement in valve function under these circumstances can be achieved either by bringing the existing shelf nearer to the anteromedial cusp or by building an artificial posterolateral ridge.

\section{(i) Annuloplasty}

This operation for the correction of mitral 


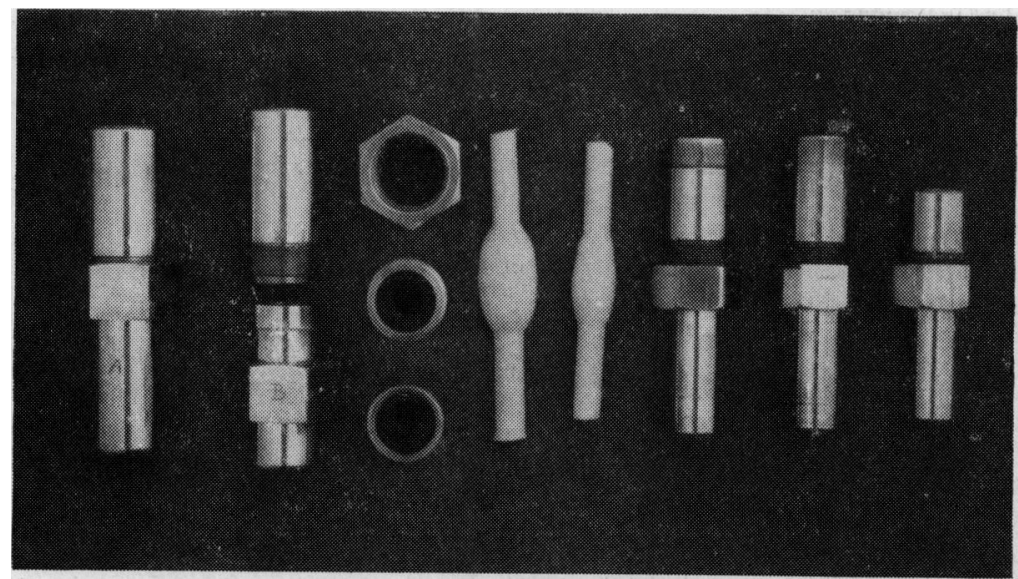

FIG. 9.-Metal moulds and dumb: bell-shaped immobile prostheses (from 'A Surgiegl Approach to Mitral Insuffciency'. C. N. Barnary, M. B. McKenzie and Schrire (196r): Brit. Y. Surg, $48,655-662)$.

regurgitation was reported by Gott and others (1957), Lillehei, Gott, DeWall and Varco (1957), Kay, Nogueira and Zimmerman (1958), and others. Competence is achieved by approximating the anteromedial cusps and the posterolateral buttress, thus shortening the distance the anteromedial leaflets must move before closing the mitral orifice. In this way one compensates for the loss of leaflet substance. The operation can only be performed when annular dilatation is mainly responsible for the leak and there is not much loss of leaflet substance. When the annulus is normal or smaller than normal in size, this manœuvre will result in stenosis of the valve.

In performing annuloplasty, silk mattress sutures are placed through the anteromedial and posterolateral portions of the annulus at one or both commissures, taking care not to damage the circumflex coronary artery, the proximal portion of the great cardiac vein or the coronary sinus which are closely related to the posterolateral portion of the ring. These stitches are tightened with the heart beating and when the two portions of the annulus have been sufficiently approximated to produce competence, the stitches are securely tied over a pillow of compressed Ivalon sponge to prevent them from tearing out at a later date.

\section{(ii) The Building of a Posterolateral Ridge}

This will take the place of the shortened, ineffective mural leaflet, especially if the anteromedial cusp is still freely mobile as is so often found. The operation has had considerable success. The function of the mural leaflet can be replaced either by an immobile or a mobile prosthesis.

(a) Immobile Prosthesis. Gott and others (1957) and Lillehei and others (1958) reported the use of an immobile prosthesis of compressed poly- vinyl sponge. Cylindrical metal moulds in severây sizes were made and an assortment of polyving cylinders prepared and sterilized. At operationca suitably-sized cylindrical prosthesis was selected and by means of three or four vertical mattress stitches of No. 2 silk secured against the ventricula surface of the posterolateral portion of the mitrin 1 annulus. In this way a buttress against which the aortic mitral leaflet could close was proviged.

We prefer the use of dumb-bell shaped Ivaling prostheses for the same purpose (Fig. 9). T每ese have the advantage that the prosthesis can be \$o placed that the widest portion of the dumb-ben 1 is situated at the area where separation of the the cusps is greatest and the thinner portion whege the separation is not so great, thus minimizirg the possibility of stenosis of this area. Furthe more, from our laboratory and clinical experienge we believe that the prosthesis should be secured against that part of the annulus which faces the mitral orifice and not on its ventricular surfagie (Fig. IO). As already pointed out, in longstanding mitral incompetence the anteromedial leaflet tends to prolapse into the atrial cavity di़्रe to loss of support from its mural leaflet. Thergfore, during ventricular systole, the anteromedial leaflet rises higher than it should so that the leaflet will overshoot the prosthesis if it is posjtioned on the ventricular surface unless the prosthesis is very large. In the latter case the prosthesis may actually produce stenosis. In thie last five patients, a dumb-bell shaped prosthes was secured in the correct position with four five vertical No. I silk mattress sutures, each tied over an Ivalon bar. The results to date haye been the best so far achieved.

(b) Mobile Prosthesis. Where both the anteromedial and posterolateral leaflets have been extensively destroyed and scarred by the rhe $\overline{\mathrm{Q}}$ matic process, resulting in little mobility of the 


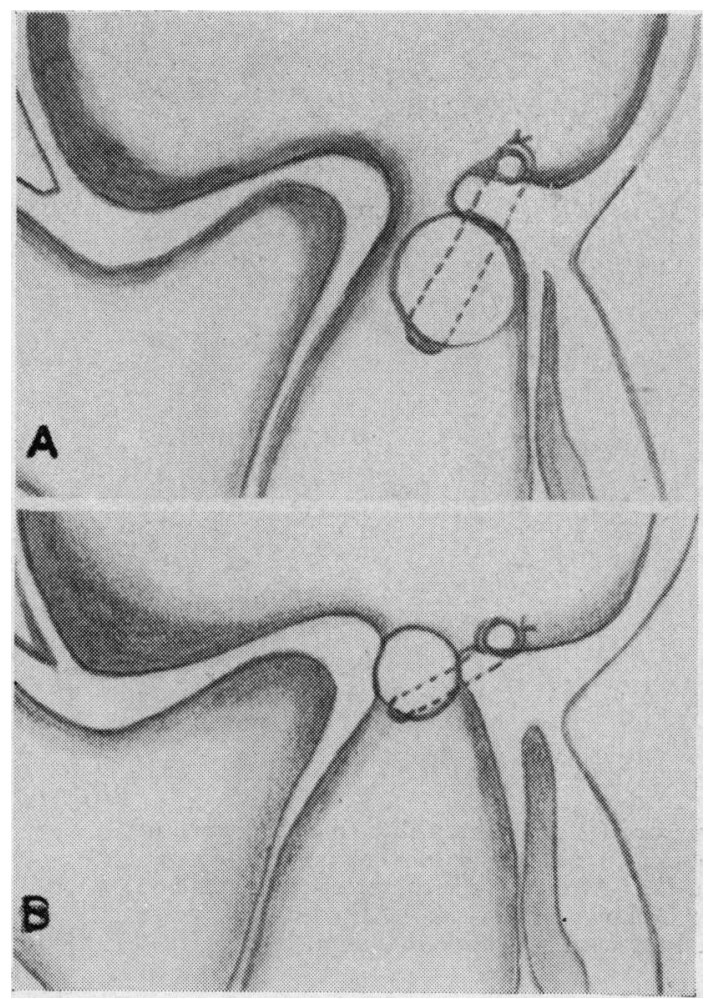

Fig. I0.-Diagram illustrating the incorrect (A) and correct (B) insertion of the prosthesis.

anteromedial leaflet, an immobile prosthesis will not correct the incompetence without producing stenosis. A mobile prosthesis is required in this type of case. It should not interfere with the valve orifice during diastole and should bulge up during systole to effect closure of the valve. Such a prosthesis has been developed in our laboratory and its use in animals is being observed (Fig. II).

\section{Insertion of a Complete Prosthesis}

In our experience there has never been any need to replace the mitral valve completely in pure mitral incompetence. Where a mixed lesion with marked stenosis and incompetence is present, both leaflets may be so destroyed and immobilized that very little valvular function can be obtained by the manœuvres described above. Complete valvular replacement will be the ideal answer to the problem. To date the results obtained when the mitral valve is completely replaced by some form of plastic valve have been very discouraging (Levowitz, Lovette, Leone, Ratan, Magovern and Kent, 1960).

\section{Results \\ Rheumatic Mitral Incompetence}

There were eight patients operated upon by one of us (C.B.) with no mortality. Annuloplasty was performed on two. The first had an initial excellent result with return to complete normality both subjectively and objectively although prior to surgery she had been incapacitated with chronic congestive cardiac failure (Barnard, McKenzie and Schrire, 196r). Five months later signs of mitral incompetence returned and progressed. Symptoms and congestive cardiac failure were precipitated by recurrence of atrial fibrillation 17 months after surgery. Death resulted from quinidine toxicity during attempted conversion to

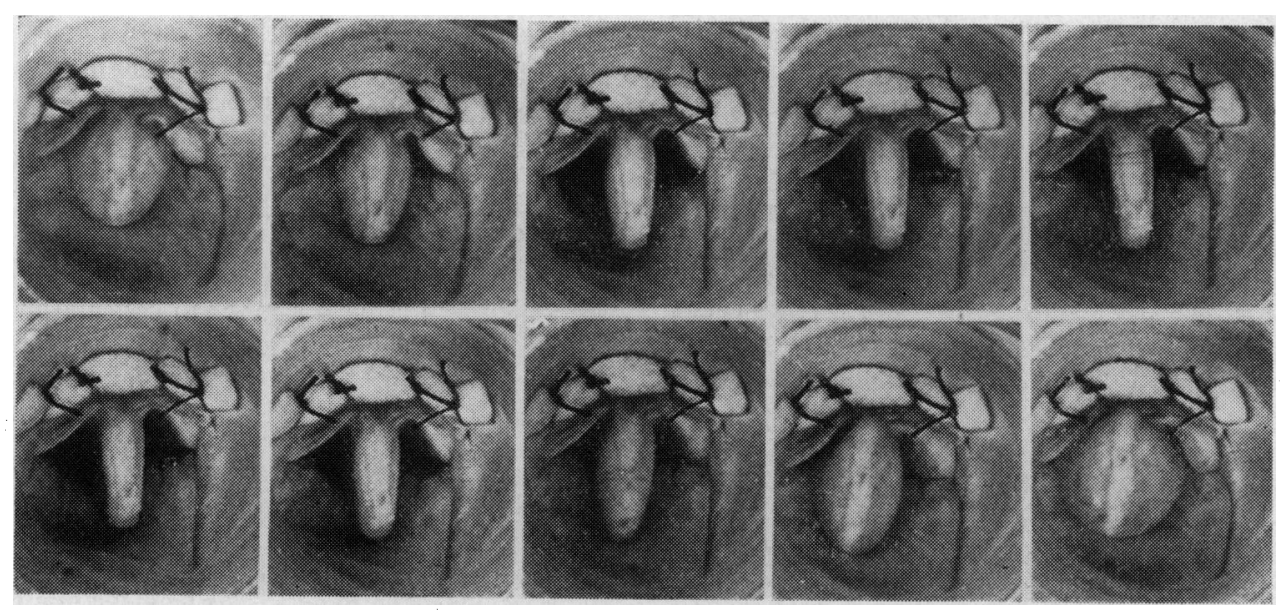

FIG. I I.-Cycle of mobile prosthesis showing the valve in the closed position, then opening and the subsequent closure. Note that the valve orifice is not obstructed during diastole (from 'A Surgical Approach to Mitral Insufficiency'. C. N. Barnard, M. B. McKenzie and V. Schrire, Brit. F. Surg., 48, 655-662, 1961). 


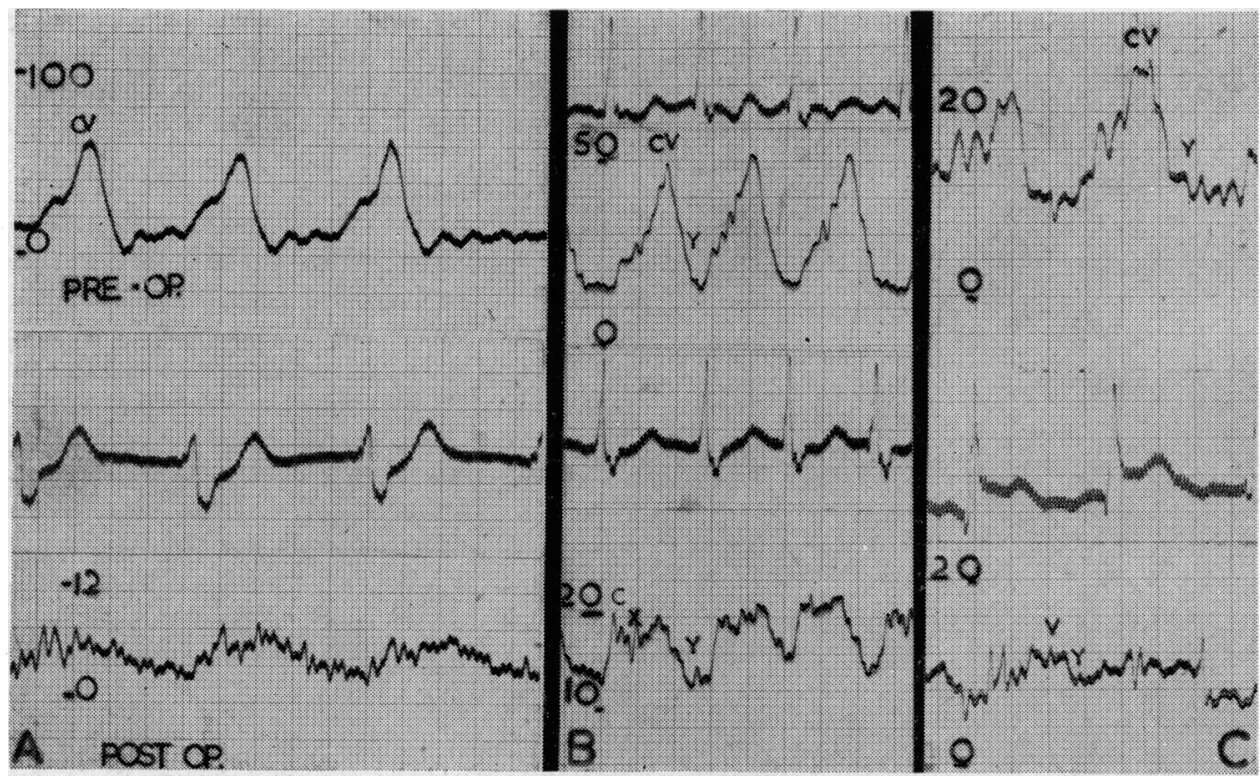

Fig. 12. - Tracing A shows an elevated left atrial pressure (LAP) mainly due to a CV wave of $44 \mathrm{~mm}$. Hg. After surgery the pressure has dropped to $8 / 4 \mathrm{~mm}$. Hg. Tracing B shows an elevated LAP mainly due to a CV wave of $30 \mathrm{~mm}$. $\mathrm{Hg}$. After surgery the pressure has halved and the CV wave is now only $5 \mathrm{~mm}$. Hg. Tracing C shows an elevated LAP with a CV wave of $15 \mathrm{~mm}$. Hg. After surgery the pressure has halved with a V wave of $4 \mathrm{~mm}$. $\mathrm{Hg}$.

sinus rhythm. Necropsy showed recurrence of gross annular dilatation with severe mitral incompetence but no suture disruption. The second patient was in the last stages of cardiac failure with enormous cardiomegaly (Fig. 3 a) prior to surgery. Within three weeks after annuloplasty and insertion of a baffle (Fig. 12a) he had recovered remarkably. While convalescing at home his symptoms suddenly recurred, 'post-pericardiotomy syndrome' with pericarditis developed and catheterization showed return of gross mitral incompetence (Fig. 4). At re-operation, three months after the first, the annuloplasty was found to have torn. Following surgery he developed staphylococcal bacterial endocarditis, cerebral embolism and died.

Six patients have had mitral valve repair with a dumb-bell shaped Ivalon prosthesis. The pressure recordings in the left atrium taken immediately post-operatively (Fig. 12) have shown a striking fall in left atrial pressure with disappearance of the mitral incompetent CV wave in all. The follow-up period varies from a few weeks to two years. Sinus rhythm has been restored by quinidine and maintained in four patients. Marked improvement has been present in every case subjectively, and in all but one objectively (Fig. I). Two patients are virtually symptom-free.

The one patient with dominant stenosis and some incompetence has made a remarkable response and is well two years after surgồ. $\vec{y}$. Inadequate valvotomy in 1953 was followed open-heart procedure in 1959 at which the cons missures were divided and the calcium remove् from the cusps which were then mobilized.

\section{Post-operative Mitral Incompetence}

Both patients had incapacitating symptoms angi one was in intractable congestive failure. In the first mitral valvotomy had been performed six years previously and pure incompetence had been produced which was repaired with an Ivalon prosthesis. Following surgery the patient re married and was travelling abroad greatly in proved a year later. The second patient had am inadequate valvotomy in 1952 with relief of symptoms until 1956. Re-valvotomy for tight stenosis in 1960 with a mechanical dilator resulted in tearing of the anterior cusp. Six weeks late. the tear in the leaflet was repaired and coms missurotomy completed with moderate improvement.

\section{Congenital Mitral Incompetence}

There were I I patients with endocardial cushion defects without ventricular septal defects and thrêe with ventricular septal defects (Barnard and Schrire, I96I) operated upon by one of us (C.B. All subjects had cleft mitral valves with varyin degrees of mitral incompetence... There was one 
death in the latter group. The importance of mobilization of the mitral leaflets and cutting the abnormal restraints was not appreciated in the first three patients. One died 48 hours after surgery of gross mitral incompetence, one has severe mitral incompetence aggravated by subacute bacterial endocarditis $2 \frac{1}{2}$ years later and one has persistent severe mitral incompetence with breakdown of the atrial septal repair. Since appropriate treatment of the mitral incompetence has been instituted only one of the nine recatheterized one year after surgery has hæmodynamic mitral incompetence or any intracardiac shunt of any consequence.

\section{Summary}

I. Mitral incompetence is now a well recognized sequel of rheumatic fever. Usually it is associated with stenosis, the degree of stenosis and incompetence differing from patient to patient. This results in a hæmodynamic spectrum varying from dominant stenosis with slight incompetence on the one hand to dominant incompetence with slight stenosis on the other, and all grades of the two between.

2. Pure mitral incompetence without stenosis is the least common. It can be recognized clinically with as much accuracy as can pure mitral stenosis. The left ventricle is enlarged, there is a loud pansystolic murmur, a third heart sound and a short mid-diastolic murmur. The electrocardiogram shows left ventricular hypertrophy and left atrial hypertrophy (if atrial fibrillation is absent) and the X-ray shows enlargement of the same two chambers.

3. The presence of both stenosis and incompetence of the mitral valve can be recognized by the combination of the signs of each, but in many cases it is difficult to assess the part played by each component. Angiocardiography promises to be the most useful investigation in solving this difficulty.

4. Mitral incompetence may develop or be aggravated by surgery for mitral stenosis. The surgeon is usually immediately aware of the dynamic disturbance produced and the patient's symptoms and signs soon confirm this impression.

5. Congenital mitral incompetence produces the same hæmodynamic disturbance as incompetence of rheumatic atiology or following bacterial endocarditis. It is most commonly associated with endocardial cushion defects. Murmurs are usually present but interpretation is often difficult. The electrocardiogram provides the most important clue to the diagnosis.

6. Normal mitral valve closure is mainly effected by the freely mobile anteromedial leaflet which closes on the less mobile posterior cusp. Incompetence of the mitral valve is produced by deficiency of leaflet tissue due to loss of tissue, to dilatation of the annulus or a combination of both. Surgery is designed at correcting this deficiency.

7. Clefts, holes or tears in the leaflets can be repaired by direct sutures or a plastic patch. Mobilization of the cusps can be achieved by separation of the fused commissures and removal of calcium. Abnormal restraints present in the cleft valves of endocardial cushion defects must be severed and chordopapillary fusion and subvalvular adhesions in rheumatic valves freed to restore mobility.

8. Most important of all is the provision of a posterolateral shelf which will effect closure and provide support for the anteromedial cusp. This can be achieved by annuloplasty or by using a prosthesis made of plastic material providing a buttress against which the anteromedial leaflet can close. The correct positioning of the prosthesis is of the greatest importance. The anteromedial leaflet tends to prolapse into the atrial cavity due to loss of support from the posterior cusp. The prosthesis should be placed against that part of the annulus which faces the mitral orifice and not on the ventricular surface. In this way it can act as an efficient buttress supporting the relatively normal anterior cusp.

9. In mixed stenosis and incompetence with gross disorganization of the valves, mobilization of the leaflets and provision of a prosthetic buttress cannot correct the incompetence without producing stenosis. The only satisfactory treatment appears to be partial or complete replacement of the valve cusps. At present a satisfactory prosthetic valve is not available and much work still needs to be done to solve this problem.

10. The results achieved in pure rheumatic mitral incompetence are reported. Annuloplasty was found to give excellent but only temporary improvement and has thus been abandoned. Repair of the valve with a dumb-bell shaped Ivalon prosthesis, provided it is large enough, has given the best and longest maintained improvement.

II. The importance of mobilizing the mitral valves freely in endocardial cushion defects and the severance of all restraints has been further substantiated.

NOTE.-Since this was written, four patients in grade 4 heart failure due to rheumatic mitral incompetence have had successful surgical repair.

We wish to thank Professor J. H. Louw of the Department of Surgery, University of Cape Town, for 
his encouraging support of our work, and the technical staff of the Marais Laboratory, Mr. C. C. Goosen, Mr. C. J. Lockett and Mrs. V. M. Commell, for their excellent work. We are grateful to the Medical Superintendent of Groote Schuur Hospital, Dr. J. G. Burger, for permission to publish. Certain illustrations are reproduced by permission of the publishers of the Britis Fournal of Surgery and Surgery. Thanks are also due $\overline{\Phi_{0}}$ the Council for Scientific and Industrial Research and the City Council of Cape Town, and to the Dr. C. E. Herman and Fourcade research grants for financhl support.

\section{REFERENCES}

Bailey, C. P., and Bolton, H. E. (1956): Criteria for and Results of Surgery for Mitral Stenosis, N.Y. med. Y., 56, 649 BARNARD, C. N. (196I): Abnormal Restraints of the Cleft Anteromedial Leaflet of the Mitral Valve in Endocardis Cushion Defects, Brit. med. F., i, 719.

—, Phillips, W. L., De Villiers, D. R., Casserley, R. D., Hewitson, R. P., Van Der Riet, R. L., and McKenzf̂, M. B. (1959): Some Experiences with Intracardiac Surgery Using the Helix-reservoir Bubble Oxygenator wiæh Total Cardio-pulmonary By-pass, S. Afr. med. Y., 33, 789.

-, and Schrire, V. (1961): The Surgical Correction of Endocardial Cushion Defects, Surgery, 49, 500.

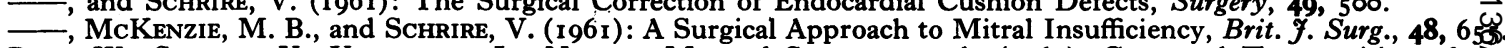

Beck, W., Schrire, V., Vogelpoel, L., Nellen, M., and Swanepoll, A. (196r): Corrected Transposition of t⿱艹 Great Vessels, Brit. Heart $\mathcal{F}$, , 23, 497.

Brock, R. C. (1952): Surgical and Pathological Anatomy of Mitral Valve, Ibid., I4, 489.

CABOT, R. C. (1926): 'Facts on the Heart'. Philadelphia: J. B. Saunders.

Cooley, J. C., Kirklin, J. W., and Harschbarger, H. G. (I957): The Surgical Treatment of Persistent Common Atrioventricular Canal, Surgery, 4r, 147.

Cooley, D. A., Latson, J. R., and KeAts, A. S. (1958): Surgical Considerations in Repair of Ventricular and Atrîn Septal Defects Utilizing Cardio-pulmonary By-pass: Experience with 104 Cases, Ibid., 43, 214.

DeWall, R. A., Warden, H. E., Lillehei, C. W., and Varco, R. L. (1956): Prothesis for Palliation of Mitral Insuffirciency, Dis. Chest, 30, 133 .

Edwards, J. E. (1960): The Problem of Mitral Insufficiency Caused by Accessory Chordæ Tendineæ in Persistent Common Atrioventricular Canal, Proc. Mayo Clin., 35, 299.

Glenn, W. W. L., Gentsch, T. O., HuMe, M., Guilfoil, P. H. (1956): Surgical Treatment of Mitral Insufficiengy with Particular Reference to Application of Vertically Suspended Graft, Surgery, 40, 59.

Glover, R. P., Henderson, A. R., Martutti, R., and Gregory, J. (1952): Surg. Forum, 178,

Gott, V. L., DeWall, R. A., Gonzalez, J. L., Hodges, P. C., VarCo, R. L., and Lillehei, C. W. (i957): The Diregtt Vision Surgical Correction of Pure Mitral Insufficiency by Use of Annuloplasty or a Valvular Prosthesis, Ezrzo. Minn. med. Bull., 29, 3, 69.

Harken, D. E., Block, H., Ellis, L. B., and Dexter, L. (I954): The Surgical Correction of Mitral Insufficiệ̂, F. thorac. Surg., 28, 604 . HendERSON, A. R., and LAw, C. L. (1953): Surgical Treatment of Mitral Insufficiency: Experimental Use of Trang
planted Pericardium in Dogs, Surgery, 33, 858 .

Johns, T. N. P., and Blalock, A. (1954): Mitral Insufficiency: Experimental Use of Mobile Polyvinyl Sponge Prosthesis, Ann. Surg., 140, 335.

KAY, E. B., and Cross, F. (1955): Surgical Treatment of Mitral Insufficiency, Surgery, $37,697$.

, Nogeuira, C., and Zimmerman, H. A. (1958): Direct Vision Correction of Mitral Insufficiency, Ibid., 44, 38.8.

Levowitz, B. S., LovetTe, J. B., Leone, M., Ratan, R. S., Magovern, G. J., and Kent, E. M. (1960): Total Prosthetic Replacement of the Mitral Valve: An Experimental Study (Abstracts of the 33rd Scientific Sessions of the American Heart Association), Circulation, 22, 779.

Lewis, Sir Thomas (1933): 'Diseases of the Chest'. London: Macmillan.

Lillehei, C. W., Gotr, V. L., Dewall, R. A., and VARCo, R. L. (1957): Surgical Correction of Pure Mitral Insufticiency by Annuloplasty Under Direct Vision, J.-Lancet, 77, 466.

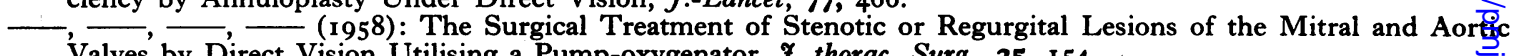
Valves by Direct Vision Utilising a Pump-oxygenator, F. thorac. Surg., 35, 154.

McKenzie, Sir James (r9i6): 'Principles of Diagnosis and Treatment of Heart Affections'. London: Oxfo⿸广d Medical Publications.

McGoon, D. C., DuShane, J. W., and Kirklin, J. W. (r959): The Surgical Treatment of Endocardial Cushigh Defects, Surgery, 46, 185 .

Moore, T. C., and SHUMACKER, H. B. (1953): Unsuitability of Transventricular Autogenous Slings for Diminishipg Valvular Insufficiency, Ibid., 33, 173 .

Nichols, H. T. (1957): Mitral Insufficiency: Treatment by Polar Cross-fusion of the Mitral Annulus Fibrosin f. thorac. Surg., 33, 102.

Nixon, P. G. F., Wooler, G. H., and Radigan, L. R. (1960): The Opening Snap in Mitral Incompetence, Brit. Heànt f., 22, 395 .

Sakakibara, S. (1955): Surgical Approach to Correction of Mitral Insufficiency, Ann. Surg., I42, I96.

Schrire, V. (1958): The Racial Incidence of Heart Disease at Groote Schuur Hospital, Cape Town: II, Hypertension

and Valvular Disease of the Heart, Amer. Heart $\mathcal{Y} ., 56,742$.
Sellors, T. H., and Somerville, W. (1961): The Persistent Ostium Primum Atrial Septal Defect, Postgrad. med. 芩, $37,646$.

Starkey, G. W. B. (1959): Surgical Experiences in the Treatment of Congenital Mitral Stenosis and Mitral Insuffciency, $\boldsymbol{F}$. thorac. Surg., 38, 336.

Steell, G. (1906): 'Textbook on Diseases of the Heart'. Manchester University Press.

Talner, N. S., Stern, A. M., and Sloan, H. E. (I96r): Congenital Mitral Insufficiency, Circulation, $23,339$.

VAN DER SPUY, J. C. (1958): The Functional and Clinical Anatomy of the Mitral Valve, Brit. Heart $\mathcal{F} ., 20,471$.

Woon; P. (1954a): Appreciation of Mitral Stenosis: Clinical Features, Brit. med. F., i, 105 I.

(1954b): : Appreciation of Mitral Stenosis: Investigations and Résults, Ibid., i, I i 13. 